\title{
Factors Influencing Dental Students' Specialty Choice: A Survey of Ten Graduating Classes at One Institution
}

\author{
Jane H. Shin, DMD; Taru H. Kinnunen, PhD; Marisa Zarchy, DMD; \\ John D. Da Silva, DMD, MPH, ScM; Brian Myung W. Chang, DDS; Robert F. Wright, DDS
}

Abstract: The aim of this study was to survey ten graduating classes at Harvard School of Dental Medicine regarding students' specialty choice and factors influencing that choice. Students were surveyed once in 2008 (for the Classes of 2007-11) and again in 2013 (for the Classes of 2012-16). A prior article reported results regarding students' interest in and experiences with prosthodontics; this article presents results regarding their interest in all dental specialties and factors influencing those interests. Of a total 176 students in the Classes of 2012-16, 143 responded to the survey, for a response rate of $81 \%$, compared to a $95 \%$ response rate (167 of total 176 students) for the Classes of 2007-11. The results showed that orthodontics was the most popular specialty choice, followed by oral and maxillofacial surgery. From the 2008 to the 2013 survey groups, there was an increase in the percentages of students planning to pursue oral and maxillofacial surgery, pediatric dentistry, and postdoctoral general dentistry. The educational debt these students expected to accrue by graduation also increased. The largest percentage of students chose "enjoyment of providing the specialty service" as the factor most influencing their specialty choice. "Prior dental school experience" and "faculty influence" were greater influences for students pursuing specialties than those pursuing postdoctoral general dentistry. Increased interest in particular disciplines may be driven by high debt burdens students face upon graduation. Factors related to mentoring especially influenced students pursuing specialties, demonstrating the importance of student experiences outside direct patient care for exposure to the work of specialists beyond the scope of predoctoral training. This finding suggests that dental schools should increase mentoring efforts to help students make career decisions based not on financial burden but rather on personal interest in the specialty, which is likely to have a more satisfying result for them in the long run.

Dr. Shin is a Periodontics Resident, Columbia University College of Dental Medicine; Dr. Kinnunen is Assistant Professor, Department of Oral Health Policy and Epidemiology, Harvard School of Dental Medicine; Dr. Zarchy is a practicing endodontist in Lansdale, PA; Dr. Da Silva is Vice Dean and Assistant Professor, Department of Restorative Dentistry and Biomaterials Sciences, Harvard School of Dental Medicine; Dr. Chang is Section Head, Maxillofacial Prosthodontics, Cleveland Clinic, Head and Neck Institute; and Dr. Wright is Professor and Chair, Department of Prosthodontics, University of North Carolina at Chapel Hill. Direct correspondence to Dr. Robert F. Wright, Department of Prosthodontics, University of North Carolina at Chapel Hill School of Dentistry, 335 Brauer Hall, Campus Box 7450, Chapel Hill, NC 27599-7450; 919-537-3435; robert_wright@unc.edu.

Keywords: dental students, career choice, dental specialties, dental education, advanced dental education, postgraduate dental education

Submitted for publication 4/4/14; accepted 8/31/14

$\mathrm{E}$ nrollment in U.S. advanced dental education programs has increased each year from 5,617 in 2006-07 to 6,667 in 2012-13. ${ }^{1}$ To some extent, the rise in applicants to residency programs may have been driven by the opening of new dental schools in the last decade. ${ }^{2}$ However, an increase in application rate was observed in only some dental disciplines. ${ }^{1}$ While endodontics and orthodontics saw a decline in applications per program, dental public health, oral and maxillofacial surgery, pediatric dentistry, periodontics, and prosthodontics experienced increases. ${ }^{1}$ Very few studies have looked at the reasons dental graduates decide to pursue certain disciplines in dentistry over others.

A pilot study conducted at Harvard School of Dental Medicine (HSDM) from October 2006 to February 2007 found that "possessing special skills/ talents unique to a specialty," "intellectual content of the specialty," and "challenging diagnostic problems" were the factors that most influenced students' decisions to select a particular dental field. ${ }^{3}$ These factors were valued more highly by students pursuing a dental specialty. Nevertheless, the authors emphasized the need for more detailed, larger scale studies looking at factors that influence specialty choice. In 2012, our group published a study that delved further into this topic at the University of Pennsylvania School of Dental Medicine (UPennSDM). ${ }^{4}$ We asked students about their specialty choice, factors that influenced their specialty choice, and their perceptions of the dental disciplines. That survey was also conducted at HSDM for the Classes of 2007-11, and results on factors influencing student interest in prosthodontics at HSDM were published in 2011. ${ }^{5}$ 
In those studies, we found that a much larger percentage of students at HSDM than at UPennSDM wanted to pursue a dental specialty. ${ }^{4,5}$ Student perspectives on dental disciplines also differed between the two schools. At UPennSDM, the greatest percentage of students perceived general dentistry as the dental discipline with the best future in terms of patient's quality of life and overall impact on the dental profession, whereas at HSDM, the greatest percentage of students chose orthodontics and oral surgery for those factors, respectively. A difference between the two dental schools that may have contributed to these findings is that the majority of the faculty at UPennSDM are general dentists, whereas instruction in the various dental disciplines at HSDM is shared by many specialists and general dentists. A study of medical students showed that many have physician role models that influence their specialty choices. ${ }^{6}$ Hence, HSDM students may meet more faculty mentors who are specialists during their predoctoral training.

In addition to mentoring, factors such as future income in the specialty, dollar value of specialty training, the public's demand for additional training in dental providers, and advances in the field also contributed to the rise in applicants to prosthodontics specialty programs. ${ }^{7}$ Similar factors may affect student career decisions in other dental disciplines. Moreover, with the economic downturn of 2008, financial factors may impact career and practice decisions as the increases in tuition and dental student debt continue to be a concern..$^{2,8}$ On the other hand, a recent study of residents in advanced education in general dentistry (AEGD) programs found that increasing knowledge and clinical skills was the most important reason for those choosing to enter an AEGD program, while opportunities for student loan deferral and the opportunity to wait for better practice opportunities following U.S. economic recovery had little influence. ${ }^{9}$

The aim of this study was to examine students' specialty choice and the factors that influenced that choice for ten graduating classes at HSDM. We surveyed the HSDM Classes of 2012-16 and compared their responses with data from our prior survey of the Classes of 2007-11. We previously published our results regarding factors influencing student interest in and experiences with prosthodontics. ${ }^{5,10}$ In this article, we present the results from the Classes of 2007-11 and 2012-16 regarding students' interest in all dental specialties and factors influencing those interests. By limiting the survey to one academic institution, we were able to identify unique characteristics of HSDM and its curriculum that may have contributed to changing student specialty interests between the Classes of 2007-11 and 2012-16. Then, by pooling the data from both class groups, we examined which factors especially influenced students pursuing certain specialties.

\section{Materials and Methods}

The research protocol for this study was reviewed and approved by the Harvard Medical School Committee on Human Studies as exempted research (IRB13-0408). In 2013, the survey used in our previous publications ${ }^{4,5}$ was sent to all 176 currently enrolled students (Classes of 2013 to 2016) and recent graduates (Class of 2012) of HSDM. An Internet-based survey program (KeySurvey, Inc., Braintree, MA, USA) was used to distribute and process completed surveys, validate and submit follow-up emails to nonrespondents, and store the resulting data in Microsoft Excel format. The survey was configured to allow only one response per respondent email address. Each potential survey respondent was given a unique link to the survey software to monitor progress and completion of the survey. Respondents were allowed to skip answers as they wished. The respondents completed the survey anonymously and voluntarily. Included in the email containing the survey link were a cover letter explaining the purpose of the survey, a statement of confidentiality, and a notice of approval and a contact at the Office for Research Subject Protection at Harvard Medical School.

Respondent information collected on the survey included class year, gender, age group, years between college and dental school, and amount of debt expected to be accrued by the end of dental school. Other survey questions were designed to generate information regarding student specialty choice and factors that influenced specialty choice.

Statistical analysis was carried out in Statistica v.10 (StatSoft Inc., Tulsa, OK, USA). Raw data were directly extracted from the KeySurvey database. Descriptive statistics are reported as proportions for categorical variables, with chi-square tests performed when contingency tables had any cell size $n \geq 10$ and Fisher exact test when $\mathrm{n}<10$. Additional descriptive statistics are reported as rank orders and frequency distributions for which no statistical significance tests were performed. 


\section{Results}

Of 176 HSDM students from the Classes of 2012-16, 143 responded to the survey, for a response rate of $81 \%$. The majority ( $94 \%$ ) of respondents were between the ages of 20 and 29 years. The female-tomale ratio was $1.5: 1$, in contrast to the 2013 national graduating seniors' female-to-male ratio of $0.96: 1 .^{11}$ The majority of these respondents (57\%) in our study had entered dental school immediately after college.

In the study conducted in $2008,{ }^{5} 167$ HSDM students from the Classes of 2007-11 responded to the survey, for a response rate of $95 \%$. The majority of those respondents (91\%) were between the ages of 20 and 29 years; the female-to-male ratio was 1.3:1; and $58 \%$ had entered dental school immediately after college. These figures were very similar to those from the respondents in the Classes of 2012-16. Although students were given the option to skip questions, there was at least a $90 \%$ response rate for each question answered by the students who participated in the survey.

\section{Specialty Choice and Influencing Factors}

Of the respondents from both survey groups who chose a specialty, most had made their decision during the third year of dental school, if not before dental school. Most students had not chosen a specialty at the time the study was conducted. There was a statistically significant increase in the percentage of undecided students from the Classes of 2007-11 to the Classes of 2012-16 ( $\mathrm{p}=0.003)$.

Orthodontics and dentofacial orthopedics was the most popular specialty choice for both survey groups. However, there was a decrease in students pursuing this specialty from $32 \%$ of respondents from the Classes of 2007-11 to 28\% from the Classes of 2012-16 (Figure 1). Oral and maxillofacial surgery maintained its rank as the second most popular specialty choice for both survey groups, with an increase from $16 \%$ to $22 \%$ in the two groups. The percentage of respondents who chose postdoctoral general dentistry also increased slightly from $13 \%$ to $15 \%$ for the two survey groups. Another notable change was the increase in popularity of pediatric dentistry from $11 \%$ to $16 \%$ of students planning to pursue this specialty from the first survey group to the second, resulting in pediatric dentistry rising above general dentistry to rank third in popularity after oral and maxillofacial surgery in 2013.

The greatest percentage of respondents in both study groups ranked "enjoyment of providing that type of specialty service" as the factor that most influenced their choice. When asked to choose all factors that influenced specialty choice, again the greatest percentage of total respondents chose "enjoyment of providing that type of specialty service" (Table 1). After this were "types of patients seen in the specialty of service" and "future salary as a professional specialist."

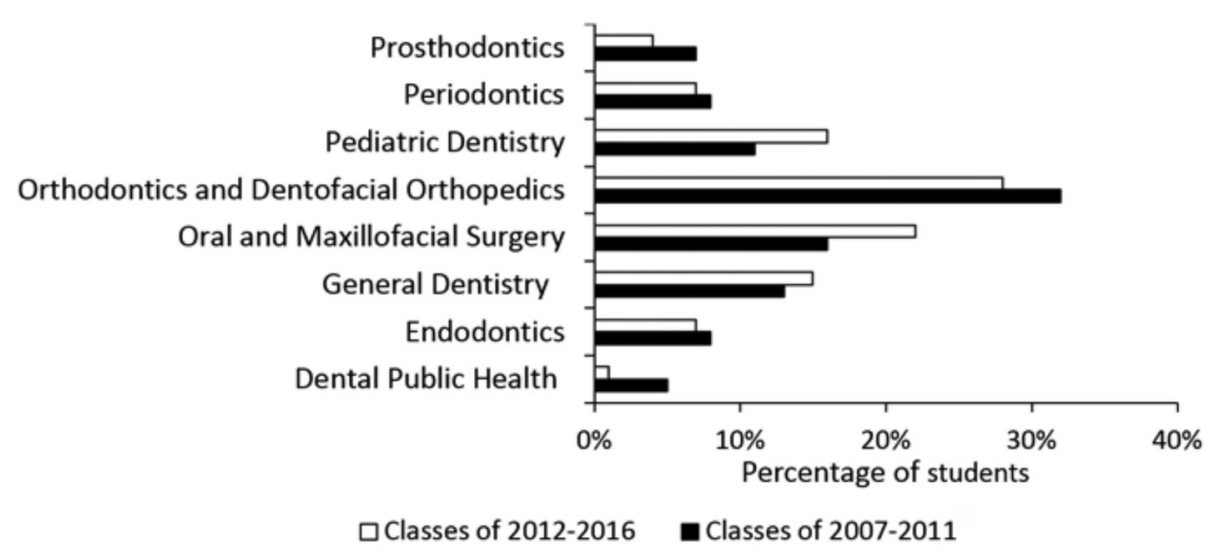

Figure 1. HSDM students' specialty choice, by number and percentage of total respondents in each survey group

Note: No respondents chose oral and maxillofacial radiology or pathology, so those categories are not shown. Data for Classes of 200711 are from Zarchy M, Kinnunen T, Chang BM, Wright RF. Increasing predoctoral dental students' motivations to specialize in prosthodontics. J Dent Educ 2011;75(9):1236-43. 
Table 1. Factors that influenced HSDM students' specialty choice, by number and percentage of total respondents in each survey group

\begin{tabular}{|c|c|c|c|c|}
\hline & \multicolumn{2}{|c|}{ Classes of 2007-11 } & \multicolumn{2}{|c|}{ Classes of 2012-16 } \\
\hline & Number & Percentage & Number & Percentage \\
\hline Enjoyment of providing that type of specialty service & 129 & $77 \%$ & 122 & $89 \%$ \\
\hline Types of patients seen in the specialty of service & 71 & $43 \%$ & 77 & $56 \%$ \\
\hline Future salary as a professional specialist & 70 & $42 \%$ & 81 & $59 \%$ \\
\hline Length of program & 53 & $32 \%$ & 63 & $46 \%$ \\
\hline Exposure prior to dental school & 44 & $26 \%$ & 60 & $44 \%$ \\
\hline Faculty influence & 34 & $20 \%$ & 42 & $31 \%$ \\
\hline Location of program & 32 & $19 \%$ & 40 & $29 \%$ \\
\hline Cost of program & 30 & $18 \%$ & 49 & $36 \%$ \\
\hline Cost of living expenses & 16 & $10 \%$ & 17 & $12 \%$ \\
\hline Other & 17 & $10 \%$ & 10 & $7 \%$ \\
\hline
\end{tabular}

Responses from the two survey groups were combined to examine the factors that influenced students planning to pursue specialties. Of the total respondents, $51 \%$ reported faculty influence was a factor influencing specialty choice (Figure 2, panel a). Respondents planning to pursue orthodontics had the highest percentage, with $63 \%$ reporting this as a factor. On the other hand, only $27 \%$ of respondents pursuing general dentistry reported faculty influence was an influencing factor, and this was statistically significant compared to the $63 \%$ pursuing orthodontics $(\mathrm{p}=0.006)$. Regarding prior dental school experience, $38 \%$ of the total respondents reported such experience was a factor influencing their specialty choice (Figure 2, panel b). Pediatric dentistry had the highest endorsement for this factor at $50 \%$ and general dentistry the lowest at $19 \%(\mathrm{p}=0.02)$. Of the total respondents, $37 \%$ reported program length as an influencing factor (Figure 2, panel c). Program length was most important to respondents pursuing general dentistry $(\mathrm{p}=0.02)$ and pediatric dentistry $(\mathrm{p}=0.05)$ and least important to those pursuing oral and maxillofacial surgery (not statistically significant).

Regarding provider enjoyment, $82 \%$ of the total respondents reported that this was a factor influencing their specialty choice (Figure 2, panel d). This was less important for respondents pursuing general dentistry and dental public health $(\mathrm{p}=0.001$ and $\mathrm{p}=0.10$, respectively). Among these respondents, $51 \%$ reported salary as an influencing factor (Figure 2, panel e). This was less important to respondents pursuing general dentistry and more important to those pursuing orthodontics $(p=0.06$ and $p=0.07$, re- spectively). In addition, $10 \%$ of the total respondents reported cost of living expenses as an influencing factor (Figure 2, panel f). This was most important to respondents pursuing general dentistry and dental public health ( $p=0.03$ and $p=0.10$, respectively). By contrast, $25 \%$ of the respondents reported cost of program as a factor influencing specialty choice (Figure 2, panel g). This factor was less important to respondents pursuing oral and maxillofacial surgery $(\mathrm{p}=0.04)$. Regarding patient type, $23 \%$ of these respondents reported patient type seen in the specialty as an influencing factor (Figure 2, panel h), but this factor was less important to respondents pursuing oral and maxillofacial surgery $(p=0.04)$. Finally, $23 \%$ of the total respondents reported program location as an influencing factor (Figure 2, panel i).

\section{Educational Debt}

Of respondents in the Classes of 2007-11, $60 \%$ reported having accrued no debt, and $28 \%$ had accrued less than $\$ 50,000$ in debt in college or professional program before entering dental school. Similarly, the majority of respondents in the Classes of 2012-16 started dental school with low student debt burdens: $72 \%$ had accrued no debt before dental school, and 23\% had accrued less than $\$ 50,000$ in debt. Students were also asked how much debt they expect to accrue by the time they graduate from dental school. In the Classes of 2007-11, the first, second, and third highest percentages of respondents (68\% altogether) reported $\$ 151,000$ to $\$ 300,000$ of expected debt (Figure 3, panel a). Interestingly, in 


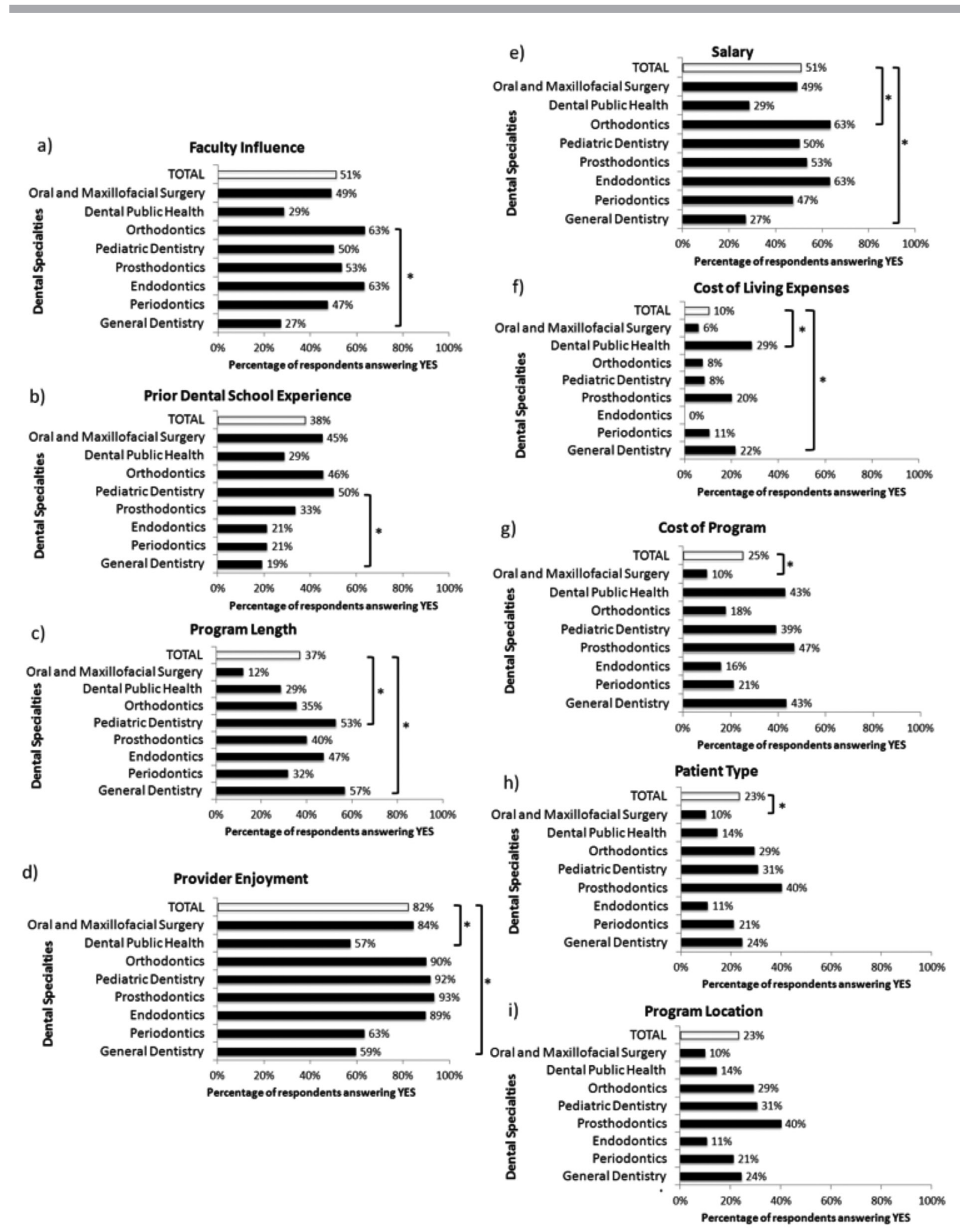

Figure 2. Factors that influenced HSDM students' specialty choice, by specialty

*Statistically significant differences were as follows, by panel: a) $p=0.006$; b) $p=0.02$; $) ~ p=0.02$ (general dentistry) and $p=0.05$ (pediatric dentistry); d) $p=0.001$ (general dentistry) and $p=0.10$ (dental public health); $e$ e) $p=0.06$ (general dentistry) and $p=0.07$ (orthodontics); f) $p=0.03$ (general dentistry) and $p=0.10$ (dental public health); g) $p=0.04$; and h) $p=0.04$. 
a)

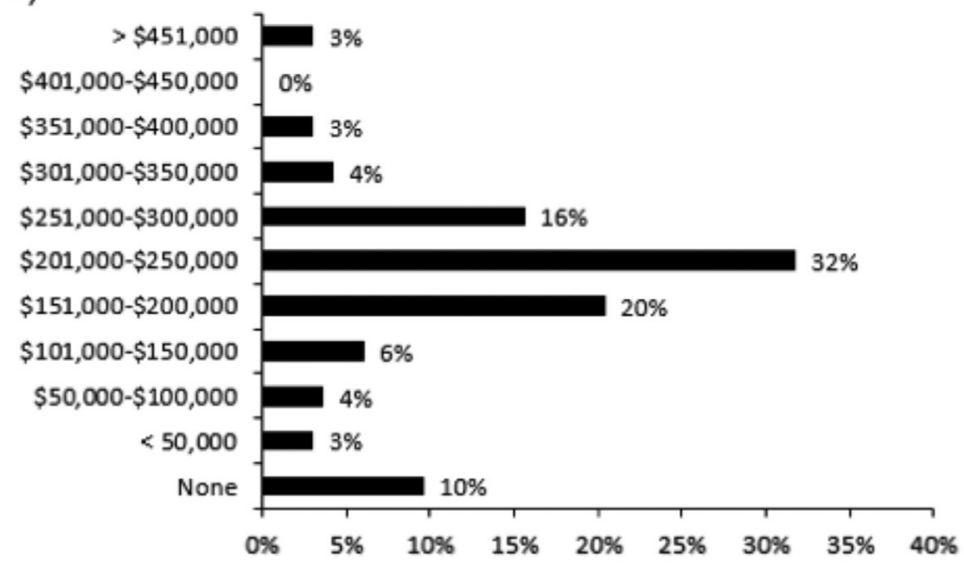

b)

Percentage of students

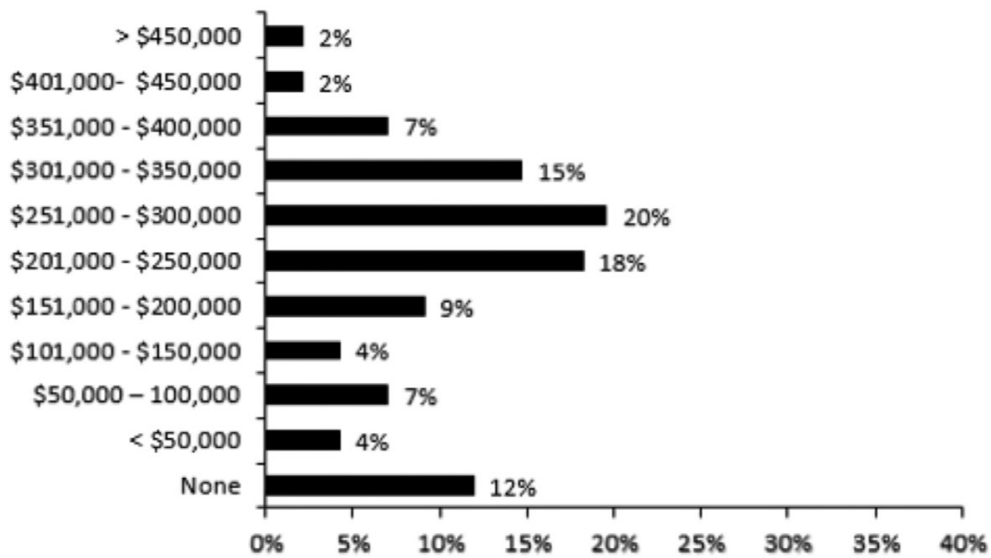

c)

Percentage of students

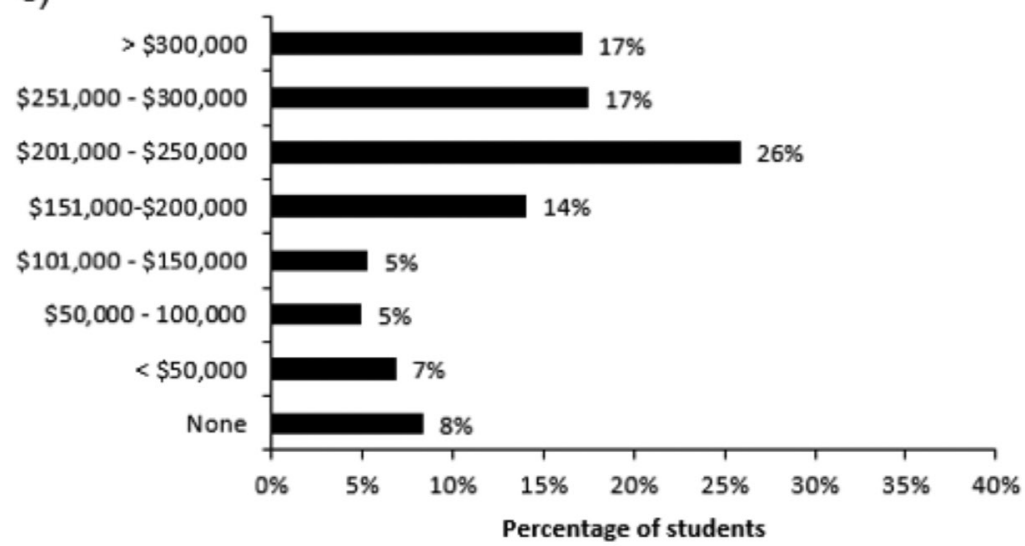

Figure 3. Debt expected to be accrued upon dental school graduation by HSDM dental students in a) Classes of 200711, b) Classes of 2012-16, and c) Classes of 2007-16 combined 
the Classes of 2012-16, this majority shifted upward, with the first, second, and third highest percentages of respondents (53\% altogether) reporting $\$ 201,000$ to $\$ 350,000$ of expected debt (Figure 3, panel b).

Combined data from the two groups showed that $8 \%$ of total respondents expected to have no debt upon graduation from dental school (Figure 3, panel c). Students planning postgraduate study in dental public health, oral and maxillofacial surgery, pediatric dentistry, and general dentistry showed the lowest percentages of those with no debt; in other words, the percentage of students with zero debt pursuing those four specialties was lower than the percentage of all students with zero debt (Table 2).

\section{Discussion}

The American Dental Education Association (ADEA) reported that $48.7 \%$ of graduating dental school seniors in 2013 applied for advanced education or dental specialty programs. ${ }^{11}$ Of this percentage, $60 \%$ chose to pursue a general practice residency (GPR) or an AEGD program. Compared to this national trend, a much larger percentage of HSDM graduates planned to pursue advanced education in one of the nine ADA-recognized dental specialties (Figure 1). Therefore, HSDM is a suitable institution to study the factors that influence dental student specialty choice.

\section{Financial Factors}

The popularity of orthodontics and the increase in the percentage of respondents pursuing general dentistry, oral and maxillofacial surgery, and pediatric dentistry may be caused by financial concerns of today's dental school graduates. Orthodontics and oral and maxillofacial surgery were the two most popular specialties (Figure 1), and these are also the two dental specialties with the highest average salaries. ${ }^{12}$ Our data showed that salary was in fact an important factor for respondents pursuing orthodontics (Figure 2, panel e).

Program length was a factor that was more important to respondents pursuing general and pediatric dentistry (Figure 2, panel c), and, according to the American Dental Association (ADA), GPR, AEGD, dental public health, and pediatric dentistry have among the shortest program lengths. ${ }^{1}$ In addition, general dentistry does not require any advanced education for practice in most states. Therefore,
Table 2. Percentage of graduating HSDM students expecting no debt upon graduation, by choice of advanced education/specialty

\begin{tabular}{lc} 
Advanced Education/Specialty & Percentage \\
\hline General Dentistry & $5 \%$ \\
Periodontics & $21 \%$ \\
Endodontics & $11 \%$ \\
Prosthodontics & $13 \%$ \\
Pediatric Dentistry & $6 \%$ \\
Orthodontics & $10 \%$ \\
Dental Public Health & 0 \\
Oral and Maxillofacial Surgery & $4 \%$ \\
\hline
\end{tabular}

although the average income for general dentists is lower than that of dental specialists, ${ }^{13}$ students pursuing these disciplines may be drawn to these fields by the ability to enter the workforce earlier. Oral and maxillofacial surgery has the longest average program length, ${ }^{1}$ which explains why respondents pursuing that specialty were less influenced by this factor (Figure 2, panel c). Moreover, a medical degree is often obtained by students in six-year oral and maxillofacial surgery programs, which may be attractive to these students and worth the longer program length.

Cost of living expenses was more important for respondents pursuing general dentistry and dental public health (Figure 2, panel f) than the other specialties, and both of these disciplines have advanced education programs offering, on average, higher firstyear stipends than those of other specialties. In fact, of the nine ADA-recognized specialties and general dentistry, the programs in oral and maxillofacial surgery, pediatric dentistry, dental public health, AEGD, and GPR are the only programs that offer average first-year stipends over $\$ 38,000 .{ }^{1}$ In addition, the cost of the program was less important for respondents pursuing oral and maxillofacial surgery (Figure 2, panel g) than the other specialties, likely because most of those programs offer higher stipends. ${ }^{1}$

These factors may be especially important in the economic environment dentists currently face. Dentists' earnings have decreased and remained down since the mid-2000s. ${ }^{14}$ This also happens at a time of increases in dental school tuition. Our data showed that most respondents began dental school with less than $\$ 50,000$ in student loan debt. ADEA reported that the average entering debt for seniors in the Class of 2013 was $\$ 45,397$, but the average amount of total educational indebtedness by dental 
school graduation was $\$ 215,145$ for these students. ${ }^{11}$ This indicates that, much like dental students across the nation, most of the debt accrued by HSDM students was from dental school. In addition, the average amount of debt accrued has shifted upwards from the Classes of 2007-11 to the Classes of 2012-16 (Figure 3, panels a and b). Total tuition and costs for all four years of dental school in the United States has increased by over $80 \%$ in the last ten years. ${ }^{15} \mathrm{~A}$ study of Canadian dental students found that students faced significantly higher debt than anticipated and their debt level influenced their career path. ${ }^{16}$ The ADA reported that the average first-year tuition in the United States is more than twice that in Canada, ${ }^{15}$ indicating that the impact of student debt may be greater for U.S. dental students. Decreased student interest in academic careers, research, or specialty training was anticipated with increased dental student debt. ${ }^{17}$ This was demonstrated in our study of UPennSDM students, which found that those with the greatest amount of expected accrued debt planned to pursue general dentistry instead of a dental specialty. ${ }^{4}$

Interestingly, the fourth highest percentage of our respondents in this study expected no debt upon graduation (Figure 3, panels a, b, and c). For only four dental disciplines - dental public health, oral and maxillofacial surgery, pediatric dentistry, and general dentistry-the percentage of students expecting no debt was lower than the overall $8 \%$ of all students expecting no debt upon graduation (Table 2). Because a lower rate of students pursuing these dental disciplines are debt-free, higher stipends offered in advanced education programs in these disciplines, as mentioned above, may be a desirable factor for students.

\section{Clinical Care Factors}

The factor that influenced the greatest percentage of the total students was "enjoyment of providing the type of specialty service" (Table 1). The handson nature of providing dental care explains why this factor is important to dental students in general and explains why it was not as much so for students pursuing dental public health (Figure 2, panel d). Students entering general dentistry were also not as influenced by this factor, since general dentistry requires a broad range of skills from different areas. The percentage of students influenced by this factor increased from $77 \%$ to $89 \%$ in the two survey groups (Table 1). In 2009, a case completion curriculum replaced HSDM's discipline-based numeric threshold system to create a more patient-centered comprehensive care practice. Analysis of this curriculum change showed that the average number of cases completed per student increased by ten as a result. ${ }^{18}$ Hence, students were able to more often experience the satisfaction patients and providers feel when seeing cases through from beginning to end.

\section{Mentoring Factors}

Respondents planning to enter pediatric dentistry were more influenced by prior dental school experience than were those interested in general dentistry (Figure 2, panel b). A possible reason is that treatment of this young age group is limited in the predoctoral clinical experience. Similarly, predoctoral HSDM students do not have much opportunity to provide orthodontic treatment during their clinical training. Hence, most of the exposure to the field is through others who do provide this specialty service, usually role models such as faculty or residents in the postgraduate program at the school. This explains the higher percentage of students pursuing orthodontics who reported being influenced by faculty than the students pursuing general dentistry who said they were influenced by faculty (Figure 2, panel a).

\section{Limitations}

This survey provides snapshots of HSDM dental students at two time points, once in 2008 and once in 2013. Student experiences would have been more standardized if surveys were conducted at a consistent time point in the predoctoral curriculum for each graduating class. In this study, we examined external factors that influence student specialty choice, but internal factors, such as students' personality type, gender, and race/ethnicity, could also influence career choices. In addition, these findings cannot be generalized to other dental schools because the study took place at only one school, where students for the most part come in with the intention of specializing.

\section{Conclusion}

This study provides important information regarding factors influencing student specialty choice at HSDM. Our survey covered students in ten graduating classes, allowing us to make comparisons between the Classes of 2007-11 and the Classes of 2012-16. The different economic environments and dental school curricula that these two subgroups 
experienced allowed us to examine the effects of these changes on the students surveyed. "Enjoyment of providing the type of specialty service" was by far the most important influencing factor in these students' specialty choice. The increase we saw in undecided students highlights opportunities for the dental school to expand mentoring efforts by faculty and clinicians of dental specialties. Mentoring can lead to increased awareness and understanding of not only the financial rewards of specialty training, but also the satisfaction clinicians and patients experience from specialty treatment and its outcomes. Such experiences can help students make career decisions based on personal interest in the specialty, instead of on the financial burdens they face upon graduation. It would be valuable to conduct this study at additional dental schools that differ in geographic location, grading system (pass/fail versus graded programs), and institutional sponsorship (private versus public schools).

\section{Acknowledgments}

The survey used in this study was developed by Dr. Marisa Zarchy as part of her research mentorship during her time at Harvard School of Dental Medicine (HSDM) with her research mentor, Dr. Robert F. Wright, who was the Advanced Graduate Education prosthodontics program director at HSDM at the time. Funding was provided by the HSDM Prosthodontics Research Fund, Division of Prosthodontics.

\section{REFERENCES}

1. American Dental Association, Survey Center. 2012-13 survey of dental education: academic programs, enrollment, and graduates. Chicago: American Dental Association, 2014.

2. Stafford GL. Dental student indebtedness: where did it come from and where will it lead? J Am Coll Dent 2013;80(4):38-48.

3. Saeed S, Jimenez M, Howell H, et al. Which factors influence students' selection of advanced graduate programs? One institution's experience. J Dent Educ 2008;72(6): 688-97.
4. Dhima M, Petropoulos VC, Han RK, et al. Dental students' perceptions of dental specialties and factors influencing specialty and career choices. J Dent Educ 2012;76(5): 562-73.

5. Zarchy M, Kinnunen T, Chang BM, Wright RF. Increasing predoctoral dental students' motivations to specialize in prosthodontics. J Dent Educ 2011;75(9):1236-43.

6. Basco WT Jr, Reigart JR. When do medical students identify career-influencing physician role models? Acad Med 2001;76(4):380-2.

7. Wright RF, Dunlop RA, Kim FM, Douglass CW. A survey of program directors: trends, challenges, and mentoring in prosthodontics, part 1. J Prosthodont 2008;17(1):69-75.

8. Walker MP, Duly SI, Beach MM, et al. Dental education economics: challenges and innovative strategies. J Dent Educ 2008;72(12):1440-9.

9. Spears R, Leite LP, Schnell RA, et al. AEGD programs: why now, why more? J Dent Educ 2013;77(1):17-23.

10. Shin JH, Kinnunen TH, Zarchy M, et al. Dental students' perceptions of and experiences with prosthodontics: ten graduating classes at one institution. J Dent Educ 2015;79(1):25-32.

11. American Dental Education Association. ADEA survey of dental school seniors, 2013 graduating class tables report. Washington, DC: American Dental Education Association, 2014.

12. United States Department of Labor, Bureau of Labor Statistics. May 2012 national occupational employment and wage estimates. At: www.bls.gov/oes/current/oes_nat. htm\#00-0000. Accessed 26 March 2014.

13. American Dental Association, Survey Center. 2012 survey of dental practice: income from the private practice of dentistry. Chicago: American Dental Association, 2013.

14. Vujicic M, Wall TP, Nasseh K, Munson B. Dentist income levels slow to recover. Health Policy Resources Center Research Brief. Chicago: American Dental Association, 2013.

15. American Dental Association, Survey Center. 2010-11 survey of dental education: tuition, admission, and attrition. Chicago: American Dental Association, 2012.

16. Walton JN, Matthew IR, Dumaresq C, Sudmant W. The burden of debt for Canadian dental students: part 4, the influence of debt on program and career decisions. J Can Dent Assoc 2006;72(10):913-913d.

17. Douglass C, Fein R. Financing dental education. J Dent Educ 1995;59(1):185-202.

18. Park SE, Timothé P, Nalliah R, et al. A case completion curriculum for clinical dental education: replacing numerical requirements with patient-based comprehensive care. J Dent Educ 2011;75(11):1411-6. 